\title{
Magnesium Deficiency Induces the Emergence of Mast Cells in the Liver of Rats
}

\author{
Satoshi TAKemoto, Akane Yamamoto, Shozo Tomonaga, \\ Masayuki FunABA and Tohru MATSU** \\ Division of Applied Biosciences, Graduate School Agriculture, Kyoto University, Kyoto 606-8502, Japan \\ (Received June 4, 2013)
}

\begin{abstract}
Summary Mast cells, multifunctional effector cells of the immune system, are implicated in the pathogenesis of hepatic steatosis and fibrosis. Magnesium $(\mathrm{Mg})$ deficiency was reported to increase triglyceride concentration in the liver, and to exacerbate the collagen deposition induced by carbon tetrachloride in the liver. Although $\mathrm{Mg}$ deficiency increases mast cells in the small intestine, the kidney and bone marrow, the effect of $\mathrm{Mg}$ deficiency on mast cells has not been clarified in the liver. We examined the emergence of mast cells in the liver of Sprague-Dawley rats given an Mg-deficient diet. Rats were fed a control diet or an Mg-deficient diet for $4 \mathrm{wk}$. Mg deficiency increased the levels of mRNA known to be expressed by mast cells in the liver; the mRNA of $\alpha$ - and $\beta$-chain high-affinity immunoglobulin E receptor $(F c \varepsilon R 1 \alpha, F c \varepsilon R 1 \beta)$, and the mRNA of mast cell protease 1 (Mcpt1), and mast cell protease 2 (Mcpt2). Histological observation showed that some mast cells were locally distributed around portal triads in the Mg-deficient group but mast cells were scarcely found in the control group. These results clearly indicate that $\mathrm{Mg}$ deficiency induces the emergence of mast cells around portal triads of the liver in Sprague-Dawley rats.
\end{abstract}

Key Words mast cell, magnesium deficiency, liver, rats

Although mast cells have been recognized to induce allergic symptoms, mast cells are now widely accepted to be multifunctional effector cells of the immune system. In rats, mast cells mainly consist of the connective tissue mast cells and the mucosal mast cells; the connective tissue mast cells express rat mast cell protease- 1 (rMCP-1) translated from Mcpt1 mRNA, and the mucosal mast cells express mast cell protease-2 (rMCP-2) translated from Mcpt2 mRNA (1). These proteases are known to have chymase activity (1).

In the liver, mast cells were suggested to contribute to fibrosis $(2,3)$; mast cells secrete transforming growth factor- $\beta$, tumor necrosis factor- $\alpha$, vascular-endothelial growth factor, and histamine, which directly or secondarily enhance fibrosis in the liver (4). Furthermore, a recent report showed that the administration of chymase inhibitor suppressed the steatosis induced by methionine and choline deficiency, suggesting the contribution of mast cells to steatosis (5).

Magnesium $(\mathrm{Mg})$ deficiency was reported to increase triglyceride concentration in the liver of rats given an AIN93G-based diet (6) or a high-sucrose diet (7). Mg deficiency was also reported to exacerbate the collagen deposition induced by carbon-tetrachloride treatment in the liver (8). Therefore, $\mathrm{Mg}$ deficiency is a stimulative factor of hepatic fibrosis and steatosis possibly via its effect on mast cells. Mg deficiency increases mast cells in the duodenum $(9,10)$, the kidney $(10)$, and bone mar-

\footnotetext{
*To whom correspondence should be addressed.

E-mail: matsui@kais.kyoto-u.ac.jp
}

row (11), but the effect of Mg deficiency on mast cells in the liver has not been reported.

In the present study, we examined the effect of $\mathrm{Mg}$ deficiency on the emergence of mast cells, and the expression of makers of the connective tissue mast cells, Mcpt 1 mRNA, and the mucosal mast cells, Mcpt2 mRNA, in the rat liver.

\section{Materials and Methods}

Animals and diets. Twelve male-specific pathogenfree Sprague-Dawley rats aged $4 \mathrm{wk}$ were purchased from Japan SLC, Inc. (Shizuoka, Japan) and cared for according to the Guide for the Care and Use of Laboratory Animals (Animal Care Committee, Kyoto University). The rats were individually housed in stainless steel cages in a temperature-, humidity- and light-controlled room $\left(24^{\circ} \mathrm{C}, 60 \%\right.$, and 12-h light/dark cycle, respectively). All rats were fed a control diet, the AIN-93G diet (12), for a 5-d adaptation period. Then the animals were divided into two groups of 6 rats given the control diet or a low-Mg diet, an AIN-93G-based diet with Mg-free AIN-93G mineral premix. The dietary Mg concentration was $499 \mathrm{mg} / \mathrm{kg}$ and $44 \mathrm{mg} / \mathrm{kg}$ in the control diet and the low-Mg diet, respectively.

The control rats were pair-fed to match the feed intake of the rats given the low-Mg diet for $4 \mathrm{wk}$. The rats were allowed free access to demineralized water during the experiment.

Sample collection. Under isoflurane anesthesia, a blood sample was obtained from the abdominal aorta with a heparinized plastic syringe at the end of the 
Table 1. Sequence of the PCR primers for amplification.

\begin{tabular}{llll}
\hline \multicolumn{1}{c}{ Genes } & \multicolumn{1}{c}{ Forward primer } & \multicolumn{1}{c}{ Reverse primer } & GenBank accession number \\
\hline FceR $1 \alpha$ & 5'-TGTGTACTTGAACGTGATGCAA-3' $^{\prime}$ & 5'-TGTCTAAGACCACGTCAGCAG-3' $^{\prime}$ & NM_012724 \\
FceR1 $\beta$ & 5'-CCCAAACCCACAAGAATCC-3' & 5'-GCCATGTCTGCTGTGGTG-3' & NM_012845 \\
Mcpt1 & 5'-GCAAAATGCAGGCCCTACTA-3' & 5'-GCGGGAGTGTGGAATAGACT-3' & NM_017145 \\
Mcpt2 & 5'-GGTCATCTGTGGTGGGTTTC-3' & 5'-TGGATTCTCGCTTTCTCACA-3' & NM_172044 \\
Gapdh & 5'-ACAACTTTGGCATCGTGGA-3' & 5'-CTTCTGAGTGGCAGTGATGG-3' & NM_017008 \\
\hline
\end{tabular}

experiment. Plasma was separated by centrifugation at $2,500 \times g$ for $30 \mathrm{~min}$ at $4^{\circ} \mathrm{C}$. The plasma samples were stored at $-20^{\circ} \mathrm{C}$ until analyses. The liver was promptly excised and washed with ice-cold isotonic saline. One part of the liver sample was placed in liquid nitrogen and stored at $-80^{\circ} \mathrm{C}$ until analyses. The other part of the liver sample was fixed in neutral $10 \%$ formalin solution (Wako Pure Chemical Industries, Ltd., Osaka, Japan).

Analyses. The plasma samples were wet-digested with trace element-grade $\mathrm{HNO}_{3}$ and $\mathrm{H}_{2} \mathrm{O}_{2}$ (Wako Pure Chemical Industries, Ltd.). Then, we determined $\mathrm{Mg}$ concentration in the plasma samples with an atomic absorption spectrophotometer (AA-6600F; Shimadzu, Kyoto, Japan).

Total RNA was extracted from the liver samples with TRIzol reagents (Life Technologies, Carlsbad, CA) according to the manufacturer's protocol. Absorbance at $260 \mathrm{~nm}$ was measured to quantify the RNA concentration, and the ratio of absorbance at $260 \mathrm{~nm}$ to that at $280 \mathrm{~nm}$ was simultaneously monitored to assess the purity of RNA. Quantitative RT-PCR was carried out using a SYBR premix Ex Taq II kit (TaKaRa, Otsu, Japan) in a Rotor-Gene 6000 (Corbett Research, Mortlake, Australia) $(13,14)$. The gene transcripts of $\alpha$ - and $\beta$-chain high-affinity immunoglobulin $\mathrm{E}$ receptor (FceR1 $\alpha$, FcER 1 $\beta$ ), Mcpt1, Mcpt2, and glyceraldehyde-3-phosphate dehydrogenase (Gapdh) were amplified by complementary DNA-specific primers (Table 1). The threshold cycle $(\mathrm{Ct})$ value was determined, and the abundance of gene transcripts was calculated from the $\mathrm{Ct}$ value using Gapdh as the corrected gene transcript.

Histological observation. Fixed samples of liver tissue were embedded in paraffin. Sections were mounted on glass slides and stained with toluidine blue. Cells containing granules with metachromasy were identified as mast cells in the liver (15).

Statistical analyses. Data are expressed as the mean \pm SE. Differences between the control group and the magnesium-deficient group were evaluated by Student's $t$ test. Statistical significance was considered to be $p<0.05$.

\section{Results and Discussion}

All rats given the low-Mg diet temporally showed skin lesions in the ears and the tail (data not shown), which is a typical sign of $\mathrm{Mg}$ deficiency in rats (14). No skin lesion was observed in the control group throughout the experiment. Plasma Mg concentration was

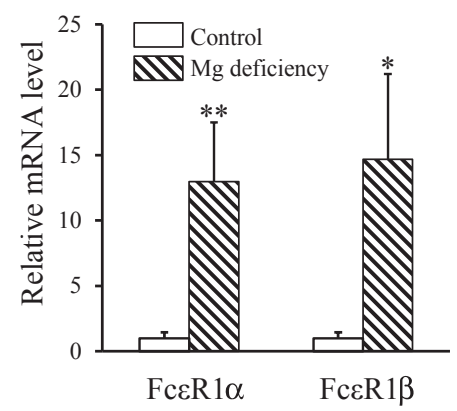

Fig. 1. Effect of Mg deficiency on the mRNA level of $F_{c} \varepsilon R 1 \alpha$ and $F_{c} \varepsilon R 1 \beta$ in the rat liver. Data are expressed as relative values with respect to the control group. Mean \pm SE $(n=6)$. Significantly different from the control group $\left({ }^{*} p<0.05,{ }^{* *} p<0.01\right)$.

$18.2 \pm 0.9 \mathrm{mg} / \mathrm{L}$ in the control rats and $7.7 \pm 0.3 \mathrm{mg} / \mathrm{L}$ in the rats given the low-Mg diet; thus the low-Mg diet significantly decreased plasma $\mathrm{Mg}$ concentration $(p<0.01)$. These results indicate that the low-Mg diet induced $\mathrm{Mg}$ deficiency.

Mast cells and basophils express FceR1 in rodents (16). The mRNA level of FceR $1 \alpha$ was increased by $\mathrm{Mg}$ deficiency in the liver $(p<0.01)$ (Fig. 1). The mRNA level of FceR $1 \beta$ was also increased by $\mathrm{Mg}$ deficiency in the liver $(p<0.05)$. The mRNA of Mcpt 1 and Mcpt 2 was not detected in the liver of the control group; the $\mathrm{Ct}$ values were more than 40 cycles in each control rat. These results are consistent with a previous report indicating that the mRNA of Mcpt1 and Mcpt2 were not detected in the liver of healthy Sprague-Dawley rats (17). On the other hand, the mRNA of Mcpt1 and Mcpt 2 were detected in all rats deficient for $\mathrm{Mg}$ and these $\mathrm{Ct}$ values were $34.7 \pm 1.4$ and $28.9 \pm 1.5$, respectively.

In toluidine blue-stained sections, some cells containing granules with metachromasy were locally observed around portal triads in the Mg-deficient group but these cells were scarcely found in the control group (Fig. 2). These results indicate that $\mathrm{Mg}$ deficiency induces the emergence of mast cells around portal triads of the rat liver.

In rats there are different main subsets of mast cells: the connective tissue mast cells expressing rMCP-1 translated from Mcpt1 mRNA, and the mucosal mast cells expressing rMCP-2 translated from Mcpt 2 mRNA (1). These proteases are known to have chymase activity in rats (1). Chan et al. (18) reported that mast cells were 

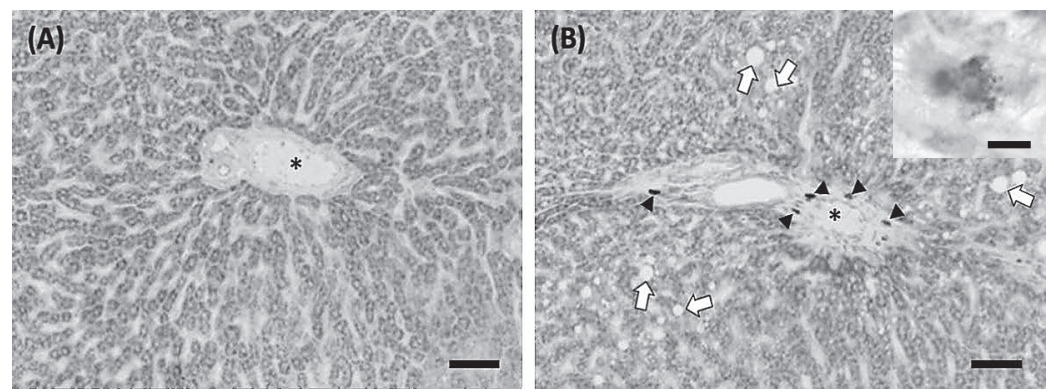

Fig 2. Representative histological appearance of toluidine blue staining of liver sections from control (A) and Mg-deficient (B) rats $(\operatorname{Bar}=50 \mu \mathrm{m})$. Arrow heads indicate mast cells. Arrows indicate enlarged vacuole. Asterisks indicate portal vein. Note that many mast cells were observed around the portal triad in the Mg-deficient rats but these cells were not observed in the control rats. A mast cell containing granules with metachromasy is shown in the inset (Bar $=5 \mu \mathrm{m})$. Enlarged fat vacuoles were located close to the portal triad of the Mg-deficient rats but such fat vacuoles were not observed in the control rats.

observed around portal triads of the liver in healthy Australian albino Wistar rats, and that these mast cells expressed rMCP-1 and/or rMCP-2, indicating that the connective tissue mast cells and the mucosal mast cells distribute around portal triads. Toluidine blue-staining does not distinguish between the connective tissue mast cells and the mucosal mast cells. However, Mg deficiency induced mast cells in the liver and the distribution of mast cell was restricted around portal triads. Furthermore, the mRNA of Mcpt1 and Mcpt2 were expressed in the liver of Mg-deficient rats but not in the liver of control rats. We conclude that $\mathrm{Mg}$ deficiency induces the connective tissue mast cells and the mucosal mast cells around portal triads. In addition, mRNA of FcER $1 \alpha$ and $F c \varepsilon R 1 \beta$ is possibly expressed by basophils slightly infiltrating to the liver of control rats but the increase in mast cells can explain the increasing expression of these mRNA in the Mg-deficient rats.

Mast cells are suggested to be implicated in the pathogenesis of hepatic fibrosis $(2,3) . \mathrm{Mg}$ deficiency itself does not affect collagen concentration in the liver but exacerbates the collagen deposition induced by a treatment with carbon-tetrachloride (8). It is likely that the emergence of mast cells does not solely induce hepatic fibrosis in the Mg-deficient rats. Liver fibrosis is a woundhealing response to chronic injury, which is characterized by excessive deposition of collagen. Thus, $\mathrm{Mg}$ deficiency possibly exacerbates the collagen deposition through inducing the emergence of mast cells when the liver is damaged.

Histological observation indicated that enlarged vacuoles, probably consisting of fat, were located close to the portal triad of the Mg-deficient rats but such vacuoles were not observed in the control rats (Fig. 2). These results are partly consistent with previous reports indicating that $\mathrm{Mg}$ deficiency increased triglyceride concentration in the liver $(6,7)$. A recent report indicated that a methionine- and choline-deficient diet increased mast cells, lipid accumulation, and chymase activity in the liver of hamsters, while the treatment with a chymase inhibitor dramatically attenuated the lipid accumulation; thus the inhibition of mast-cell activity attenu- ates hepatic steatosis induced by the methionine- and choline-deficient diet (5). Hamster chymase efficiently converts angiotensin I to angiotensin II, which has been hypothesized to induce hepatic steatosis (5). Rat chymase, rMCP-1, also activates angiotensin II production (19); Mg deficiency increases chymase expression at the transcription level by mast cells in the rat liver, which possibly increases triglyceride accumulation.

The present experiment indicated that $\mathrm{Mg}$ deficiency increased the number of mast cells and the mRNA expression of chymases in the liver. Further study is necessary for clarifying the involvement of hepatic mast cells and chymase in the effect of Mg deficiency on the liver, i.e., the increase in lipid accumulation and the exacerbation of collagen deposition.

\section{REFERENCES}

1) Pejler G, Abrink M, Ringvall M, Wernersson S. 2007. Mast cell proteases. Adv Immunol 95: 167-255.

2) Yamashiro M, Kouda W, Kono N, Tsuneyama K, Matsui O, Nakanuma Y. 1998. Distribution of intrahepatic mast cells in various hepatobiliary disorders. An immunohistochemical study. Virchows Arch 433: 471-479.

3) Farrell DJ, Hines JE, Walls AF, Kelly PJ, Bennett MK, Burt AD. 1995. Intrahepatic mast cells in chronic liver diseases. Hepatology 22: 1175-1181.

4) Franceschini B, Ceva-Grimaldi G, Russo C, Dioguardi N, Grizzi F. 2006. The complex functions of mast cells in chronic human liver diseases. Dig Dis Sci $\mathbf{5 1}$ 2248-2256.

5) Masubuchi S, Takai S, Jin D, Tashiro K, Komeda K, Li ZL, Otsuki Y, Okamura H, Hayashi M, Uchiyama K. 2012. Chymase inhibitor ameliorates hepatic steatosis and fibrosis on established non-alcoholic steatohepatitis in hamsters fed a methionine- and choline-deficient diet. Hepatol Res 43: 970-978.

6) Akiyama S, Uehara M, Katsumata S, Ihara H, Hashizume N, Suzuki K. 2008. Effects of dietary ascorbic acid supplementation on lipid peroxidation and the lipid content in the liver and serum of magnesium-deficient rats. Magnes Res 21: 232-236.

7) Rayssiguier Y, Gueux E, Weiser D. 1981. Effect of magnesium deficiency on lipid metabolism in rats fed a high carbohydrate diet. J Nutr 111: 1876-1883. 
8) Rayssiguier Y, Chevalier F, Bonnet M, Kopp J, Durlach J. 1985. Influence of magnesium deficiency on liver collagen after carbon tetrachloride or ethanol administration to rats. J Nutr 115: 1656-1662.

9) Kraeuter SL, Schwartz R. 1980. Blood and mast cell histamine levels in magnesium-deficient rats. J Nutr 110: 851-858.

10) Veilleux R. 1975. Mast cell increase in the duodenum and kidney of magnesium-deficient rats. Lab Invest 33: 80-87.

11) Bélanger LF. 1977. Variations in the mast cell population of skin and bone marrow in magnesium-deprived rats. The influence of sex hormones. J Nutr 107: 2164-2170.

12) Reeves PG. 1997. Components of the AIN-93 diets as improvements in the AIN-76A diet. J Nutr 127: S838-S841.

13) Suenaga M, Matsui T, Funaba M. 2010. BMP inhibition with dorsomorphin limits adipogenic potential of preadipocytes. J Vet Med Sci 72: 373-377.

14) Kotani M, Kim KH, Ishizaki N, Funaba M, Matsui T.
2013. Magnesium and calcium deficiencies additively increase zinc concentrations and metallothionein expression in the rat liver. Br J Nutr 109: 425-432.

15) Sridharan G, Shankar AA. 2012. Toluidine blue: A review of its chemistry and clinical utility. J Oral Maxillofac Pathol 16: 251-255.

16) Kinet JP. 1999. The high-affinity IgE receptor (FceRI): from physiology to pathology. Annu Rev Immunol 17: 931-972.

17) Lützelschwab C, Pejler G, Aveskogh M, Hellman L. 1997. Secretory granule proteases in rat mast cells. Cloning of 10 different serine proteases and a carboxypeptidase A from various rat mast cell populations. J Exp Med 185: $13-29$.

18) Chan A, Cooley MA, Collins AM. 2001. Mast cells in the rat liver are phenotypically heterogeneous and exhibit features of immaturity. Immunol Cell Biol 79: 35-40.

19) Kunori $Y$, Muroga $Y$, Iidaka M, Mitsuhashi H, Kamimura T, Fukamizu A. 2005. Species differences in angiotensin II generation and degradation by mast cell chymases. J Recept Signal Transduct Res 25: 35-44. 